\title{
Heat transport pathways into the Arctic and their connections to surface air temperatures
}

\author{
Daniel Mewes and Christoph Jacobi \\ Leipzig Institute for Meteorology, Universität Leipzig, Leipzig, Germany \\ Correspondence: Daniel Mewes (daniel.mewes@uni-leipzig.de)
}

Received: 26 June 2018 - Discussion started: 20 August 2018

Revised: 11 March 2019 - Accepted: 12 March 2019 - Published: 27 March 2019

\begin{abstract}
Arctic amplification causes the meridional temperature gradient between middle and high latitudes to decrease. Through this decrease the large-scale circulation in the midlatitudes may change and therefore the meridional transport of heat and moisture increases. This in turn may increase Arctic warming even further. To investigate patterns of Arctic temperature, horizontal transports and their changes in time, we analysed ERA-Interim daily winter data of vertically integrated horizontal moist static energy transport using self-organizing maps (SOMs). Three general transport pathways have been identified: the North Atlantic pathway with transport mainly over the northern Atlantic, the North Pacific pathway with transport from the Pacific region, and the Siberian pathway with transport towards the Arctic over the eastern Siberian region. Transports that originate from the North Pacific are connected to negative temperature anomalies over the central Arctic. These North Pacific pathways have been becoming less frequent during the last decades. Patterns with origin of transport in Siberia are found to have no trend and show cold temperature anomalies north of Svalbard. It was found that transport patterns that favour transport through the North Atlantic into the central Arctic are connected to positive temperature anomalies over large regions of the Arctic. These temperature anomalies resemble the warm Arctic-cold continents pattern. Further, it could be shown that transport through the North Atlantic has been becoming more frequent during the last decades.
\end{abstract}

\section{Introduction}

The Arctic regions play a significant and specific role in climate change. Here, the temperature increases much faster compared to the rest of the globe (Stroeve et al., 2012; Wendisch et al., 2017), which is called Arctic amplification. This stronger warming is mainly caused by loss of sea ice and the consequent increased exposure of the Arctic ocean to the atmosphere.

Following these changes in temperature and sea ice cover it was found that the sea level pressure (SLP) decreases over the Arctic in the winter season (Gillet et al., 2003; Screen et al., 2014). This itself might alter the circulation and thus the transport of air masses into and out of the Arctic. Analyses of the decadal variability in EC-Earth model (Hazeleger et al., 2012) runs showed that in a warmer climate the Aleutian Low intensifies during winter months, which changes the circulation patterns (Linden et al., 2017). The decrease in the temperature difference between the Arctic and midlatitudes due to Arctic amplification is suggested to be followed by a change in the meridional transport of heat into the Arctic, which has been seen in reanalysis data (Graversen, 2006; Vinogradova, 2007). Analysis of regional climate model output has shown that at the end of the 21 st century the seasonal mean layer thickness between 1000 and $300 \mathrm{hPa}$ over the Arctic will likely increase significantly, while the interannual variability increases (Rinke and Dethloff, 2008). To summarize, there is an indication that Arctic amplification may alter the circulation and heat transport patterns in the Arctic.

To understand how circulation and transport are connected to other meteorological variables, the self-organizing map (SOM) method has been shown to be a viable cluster and pattern extraction tool (Liu et al., 2006; Liu and Weisberg, 
2011). Cassano et al. (2006) evaluated model representations and projections of the SLP patterns over the Arctic. Corresponding temperature and precipitation anomalies have been attributed to the respective patterns that have emerged from SOM analyses. They found that SLP patterns that feature an extended North Atlantic storm track and a strong Aleutian Low are connected to positive temperature anomalies. Negative precipitation anomalies over the North Atlantic were found for SLP patterns with generally high SLP. Skific et al. (2009) used SOM analyses to validate performance of the Community Climate System Model (CCSM). They showed that the model successfully captures major SLP patterns, which has been derived by the SOM from the European Centre for Medium-Range Weather Forecasts (ECMWF) reanalysis data ERA-40. Additionally, they found through relating moisture transports to particular circulation regimes that by the late 21 st century the transport is projected to be increased within the CCSM3. The SOM method was also used by Higgins and Cassano (2009) to determine the influence of reduced sea ice on the geopotential height of $1000 \mathrm{hPa}$ over the Arctic using the Community Atmosphere Model (CAM3) (Collins et al., 2006). They found that with reduced sea ice the geopotential height of $1000 \mathrm{hPa}$ increases over Siberia, the Greenland Sea, and the Norwegian Sea.

Lynch et al. (2016) used the SOM method to evaluate the connection between SLP patterns and the connection to high and low sea ice cover in the Pacific sector. They showed that the years with a low ice fraction are connected to positive temperature anomalies and transport originating from the south, while the years with a high ice concentration are connected to the transport of ice from regions in the north even though the ice itself is melting.

Mattingly et al. (2016) have analysed the tropospheric meridional moisture transport over Greenland using the SOM method and found that from 2000 to 2015 positive moisture transport anomaly patterns towards Greenland were more common compared to the years 1979 to 1994, and thus might have increased the melting of the Greenland ice sheet.

The following question remains: to which degree are different heat transport pathways into the Arctic are responsible for the increased Arctic warming? In this study we therefore focus on the moist static energy (MSE) transport pathways into the Arctic in the winter months and on the corresponding temperatures over the Arctic by using the SOM method. Winter was chosen as the Arctic temperature is most sensitive to influences through transports in this season (Yoshimori et al., 2017). We use ERA-Interim reanalyses (Dee et al., 2011; ECMWF, 2017) for clustering the vertically integrated MSE transport. Furthermore, the temporal evolution of occurrence frequencies for the patterns obtained is analysed, as well as the corresponding temperature anomalies for the Arctic region. In Sect. 2 the data used and SOM method are presented. The results are found in Sect. 3, and are followed by a discussion in Sect. 4 . Section 5 concludes the paper.

\section{Method and data}

\subsection{Data}

In this study daily mean ERA-Interim (Dee et al., 2011) data were analysed for the winter months (December to February) from 1979 to 2016. Data were provided at a horizontal grid resolution of $0.75^{\circ} \times 0.75^{\circ}$ on 60 vertical levels by ECMWF (2017). ERA-Interim was chosen as it well represents the temperature in the Arctic (Chaudhuri et al., 2014; Simmons and Paul, 2015). Daily means were calculated from 6-hourly output. The vertically integrated daily horizontal MSE transport MSET is calculated at each grid point as follows:

$$
\begin{aligned}
\text { MSET }= & \frac{1}{g} \int_{\eta_{\mathrm{sfc}}}^{\eta_{200 \mathrm{hPa}}} \boldsymbol{v}(\eta)\left(c_{p} T(\eta)+g z(\eta)\right. \\
& +L q(\eta)) \frac{\partial p}{\partial \eta} \mathrm{d} \eta .
\end{aligned}
$$

Here, $g$ is the gravitational acceleration (taken as $\left.9.81 \mathrm{~m} \mathrm{~s}^{-2}\right), \boldsymbol{v}$ is the horizontal wind vector, $c_{p}$ is the specific heat constant at constant pressure, $T$ is the temperature, $z$ is the geopotential height, $L$ is the latent heat of vaporization of water, $q$ is the specific humidity, $\eta$ is the model level, and $p$ is the pressure. The integration limits from the surface to the $200 \mathrm{hPa}$ level were chosen to obtain the heat transport throughout the entire troposphere. Further analysis was performed only on data north of $50^{\circ} \mathrm{N}$.

\subsection{Self-organizing maps}

The SOM is an artificial neural network developed by Kohonen (1998), and it is used to reduce the dimensionality of a data set by organizing it in a two-dimensional array, called a map. SOMs were created by using the python package "somoclu" (Wittek et al., 2017). A general advantage of a SOM is that it is not limited by linear assumptions. Furthermore, the SOM method has advantages over PCA and (rotated) EOF analysis in finding patterns in data. (Reusch et al., 2005; Liu and Weisberg, 2011). SOMs are used as a cluster analysis tool that, broadly speaking, is built to minimize the within cluster difference while maximizing the between cluster difference. The SOM method is different in the way that neighbouring clusters within this two-dimensional map are more similar to each other than to clusters that are farther apart from each other. This is achieved by a characteristic of the SOM where the clusters also develop depending upon the neighbouring clusters, and thus retain the general topology of the multidimensional data it is used on. Eventually, each cluster represents a set of the given data.

The SOM was used to analyse the tropospheric horizontal MSE transport calculated from ERA-Interim. The SOM clustering is used to find common transport features in the Arctic. Generally, the patterns emerge from the data due to the fact that the patterns try to minimize the within pattern 
variance. This is done by comparing each daily data field with each pattern, and finding the pattern with the smallest Euclidean distance to the given daily data field. Euclidean distances are calculated between the vectorized field of the two-dimensional MSE transport north of $50^{\circ} \mathrm{N}$ and the vectorized emerging patterns of the SOM method for each iteration during the learning process.

Further, the $2 \mathrm{~m}$ air temperature anomalies corresponding to the clustering of the tropospheric MSE transport are analysed. This is done to obtain the respective transport effect on the temperature depending on the different transport features. As with a lot of other clustering algorithms, the choice of the right number of patterns to be extracted is partly subjective. A SOM with the size of 4 columns $\times 3$ rows was chosen for our analysis of MSE transport into the Arctic Ocean; it provided the best balance of generalization without losing too many distinct states. In addition to the clustering of the SOM itself, we chose to group similar transport patterns that have emerged from the SOM manually.

Grouping the patterns is common in the literature (e.g. Mattingly et al., 2016; Higgins and Cassano, 2009). This serves to ease the discussion and provides the option to decide upon which patterns fit best, which is not only based on the underlying Euclidean distances of the vectorized fields. The mathematical idea behind manual grouping instead of using a smaller SOM size is due to the characteristics of Euclidean distance; it is possible that when using smaller SOM sizes, distinct daily data fields might be gathered in clusters that do not represent them well from a meteorological point of view. The meteorological point of view in our case would be the general direction and rotations of the two-dimensional vector field of the MSE transport. For other fields these might differ (e.g. for clustering temperature fields the meteorological point of view would be that slightly shifted maxima might cause big differences in the Euclidean distance). We decided to group them manually to make sure that patterns that fit from a meteorological point of view are gathered within a group, and thus share features that are more relatable to each other. SOM was chosen in favour of other techniques (e.g. $k$ means) because the patterns emerging from a SOM are easier to relate to each other; similar structures of data are kept next to each other within the emerging arrangements of patterns.

\section{Results}

\subsection{Heat transport SOM}

The SOM of the vertically integrated MSE transport is shown in Fig. 1. Each pattern features different transport strengths and directions as shown by the vectors.

For a view on the general transport pathways we decided to further gather the patterns into three groups chosen according to the horizontal transport from middle latitudes into the Arctic. Thereby, we grouped patterns that show similar hor- izontal transport features to distinguish the respective composites for each of the three major patterns found. The manual grouping was based on the directions and rotations of the two-dimensional vector fields. This manual grouping leads to a more transparent view on the actual clustering of the data.

The composite transports are shown in Fig. 2. They were derived by adding the distinct patterns of each group in Fig. 1 weighted by their relative frequency of occurrence. Subsequently, we will call them the North Atlantic pathway, the Siberian pathway, and the North Pacific pathway.

The red framed patterns in Figs. 1 and 2 show the North Atlantic pathway. Corresponding patterns for the North Atlantic pathway are patterns 1.1, 1.2, 1.3 and 2.2. These patterns share a heat transport that is moving from the North Atlantic either over Greenland or through the Fram Strait and over Svalbard into the central Arctic.

Patterns with a green frame correspond to transport that originates in central Siberia or northern Siberia and is directed into the central Arctic by a cyclone motion with its centre over the Kara Sea, the Laptev Sea, or the North Pole. These features are summarized as the Siberian pathway. The Siberian pathway consists of the patterns 2.1, 3.1, and 3.2. The transport structure of Pattern 2.1 is mainly zonal within the central Arctic, and no strong meridional transport is present. However, its general structure with a centre of cyclonic motion fits best to the Siberian pathway group.

The North Pacific pathway (blue frames) arises from the patterns 1.4, 2.3, 2.4, 3.3, and 3.4. The main transport occurs from the North Pacific through eastern Siberia into the central Arctic. This occurs mostly with one centre of anticlockwise transports at the Barents Sea or Laptev Sea and the other centre over the Northwest Passage. In some cases (see patterns 1.4, 2.3, and 2.4) clockwise transports with the centre north of the Bering Strait or within the central Arctic are present.

Due to grouping, the mean within cluster variance has changed from $2.2 \times 10^{22} \mathrm{~J} \mathrm{~m} \mathrm{~s}^{-1}$ for the $12 \mathrm{SOM}$ clusters to $2.7 \times 10^{22} \mathrm{~J} \mathrm{~m} \mathrm{~s}^{-1}$ for the three pathways.

\subsection{Temperature anomaly composites according to transport pathways}

Figure 3 shows the composites of the $2 \mathrm{~m}$ temperature anomalies corresponding to the respective pathways. Temperature anomalies were calculated as deviations from the winter mean period from 1979 to 2016.

The North Atlantic pathway related temperature anomalies (Fig. 3a) show increased temperature from the North Atlantic into the central Arctic with a maximum greater than $6 \mathrm{~K}$ north of Svalbard. For northern Canada, the Bering Strait and central Siberia a cold anomaly is observed with a minimum of $-3.5 \mathrm{~K}$ at the Bering Strait and north of Lake Baikal. The negative anomaly in Siberia results from the increased transport over the North Atlantic, which results in a decrease in 

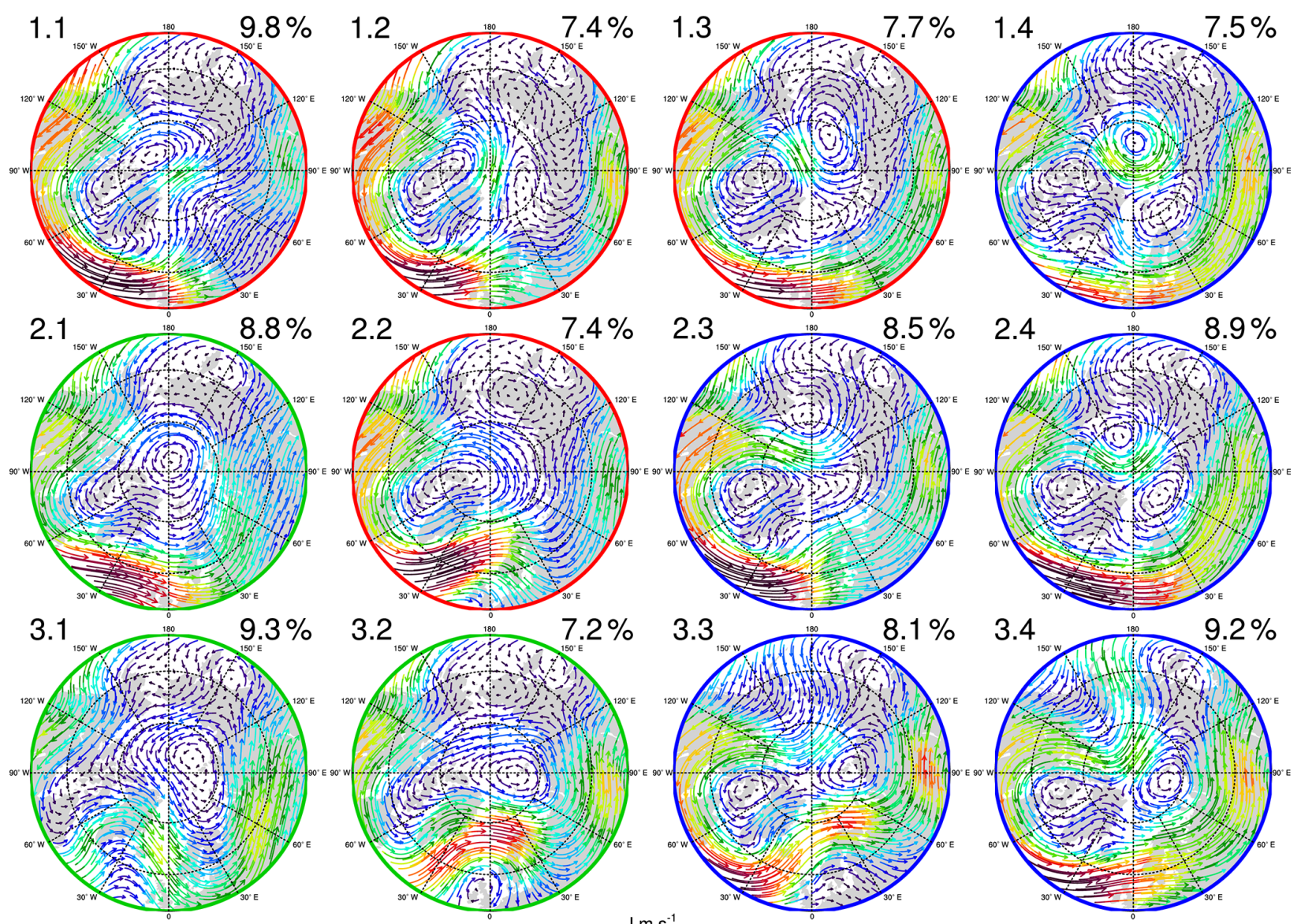

$2 e+10 \quad 6 e+10$

$1 e+11$

$\mathrm{J} \mathrm{m} \mathrm{s}^{-1}$

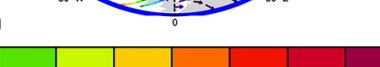

$3.4 \mathrm{e}+11 \quad 3.8 \mathrm{e}+11$

Figure 1. SOM with 4 columns and 3 rows of vertically integrated (200-1000 hPa) horizontal MSE transport (MSET) from winter ERAInterim data (1979-2016). Numbers on the top left of each SOM are used to name different patterns, percentages in the top right of each pattern correspond to the relative frequency of occurrence during the analysed time period. The maps are centred at $0^{\circ} \mathrm{E}$. The vectors show the vertically integrated horizontal MSET. Red vectors correspond to large magnitudes of MSET, while blue vectors correspond to small magnitudes of MSET. Differently coloured frames indicate patterns that were grouped together.

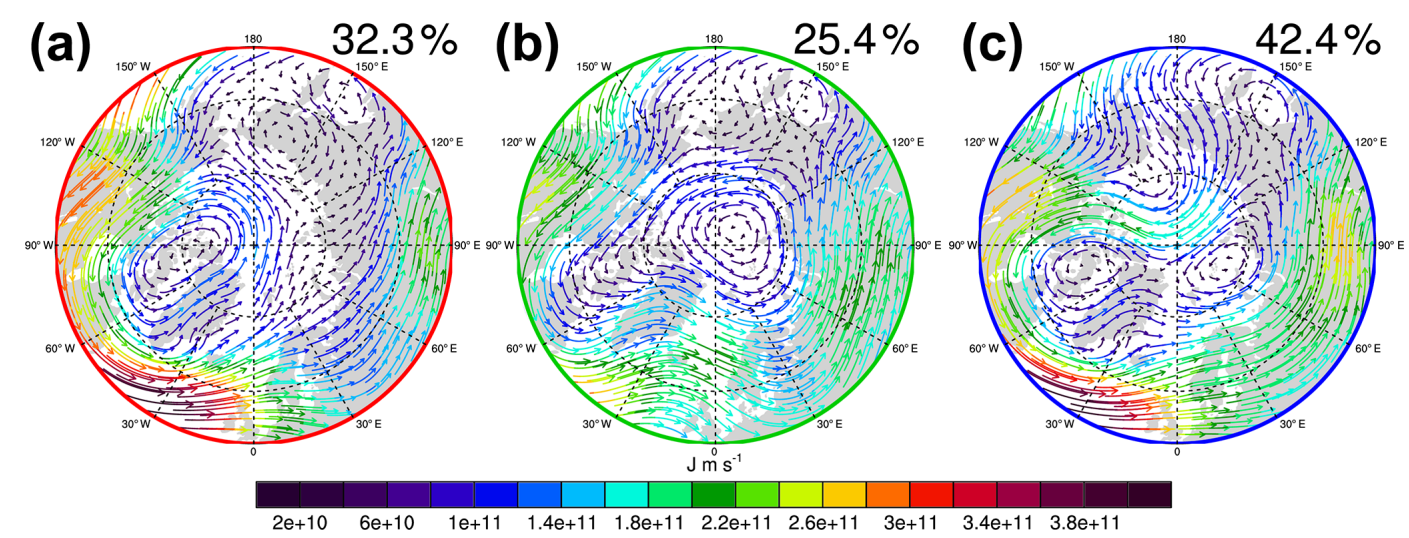

Figure 2. The three different transport pathways: the North Atlantic pathway (a; red coloured frame), the Siberian pathway (b; green coloured frame), and the North Pacific pathway (c; blue coloured frame), derived from the composites of the selected patterns of Fig. 1 weighted by their relative frequency of occurrence within the group. 


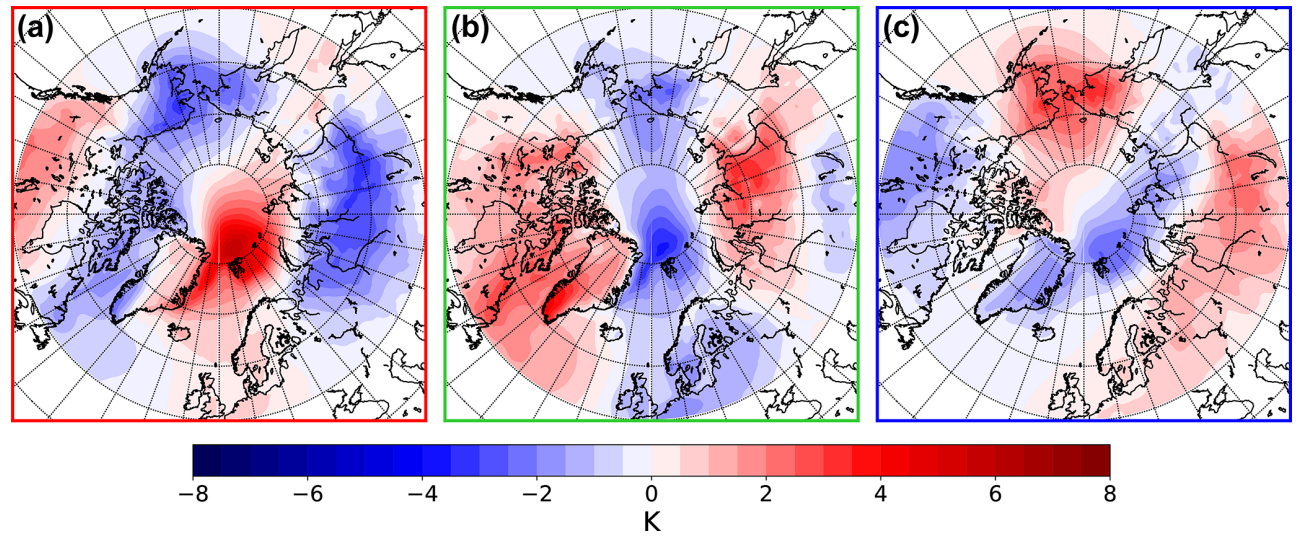

Figure 3. Composite of $2 \mathrm{~m}$ temperature anomalies for the three pathways: the North Atlantic pathway (a; red coloured frame), the Siberian pathway (b; green coloured frame), and the North Pacific pathway (c; blue coloured frame). Contour spacings show temperature anomalies in $0.5 \mathrm{~K}$. Blue colours indicate a cold anomaly and red colours indicate a warm anomaly compared to the mean of the analysed time frame.

zonal transport of MSE to Siberia, and in an increase in the transport of cold air from the north.

The Siberian pathway (Fig. 3b) is connected to higher temperatures over Siberia, as well as with warm anomalies over North America and Greenland with temperature anomalies greater than $5 \mathrm{~K}$ at the southern tip of Greenland. Negative temperature anomalies occur over northern Europe, through the Fram Strait and Svalbard into the central Arctic, the Chukchi Sea, and the Bering Strait, with anomalies as low as $-4 \mathrm{~K}$ north of Svalbard. This temperature pattern occurs because of the limited MSE transport through the North Atlantic, and the more zonally favoured transport over Europe and Siberia.

The North Pacific pathway (Fig. 3c) composite shows increased temperature over large parts of Eurasia connected to zonal transport over the continent. Positive temperature anomalies are also seen over the Bering Strait and the Chukchi Sea (up to $4 \mathrm{~K}$ ) together with northward transport (Fig. 2c). A cooling effect is observed from North America over Greenland, and Svalbard to the Laptev Sea, with the maximum of $-3 \mathrm{~K}$ west of Svalbard.

Figure 4 shows the composites of the vertically averaged (surface to $200 \mathrm{hPa}$ ) potential temperature anomalies corresponding to the respective pathways. As vertically integrated transports are analysed, the vertical averaged potential temperature shall provide a more relatable quantity compared to the $2 \mathrm{~m}$ temperature.

Generally, the vertically averaged potential temperature anomalies show very similar structures compared to those of the $2 \mathrm{~m}$ temperatures for all of the pathways. The general maximum amplitude of the vertically averaged potential temperature anomalies is smaller by a factor of 2 . This shows that the corresponding $2 \mathrm{~m}$ temperature anomaly fields for each pathway are a good indicator of the vertically averaged potential temperature within the troposphere. However, the specific locations of maxima and minima are slightly shifted for the Siberian pathway, which does not show a clear negative anomaly north of Svalbard but an elongated region of negative anomaly of potential temperature.

\subsection{Meridional heat transport}

In order to more clearly show the transport of MSE into the Arctic through the three identified patterns, we analysed the longitudinal distribution of the meridional component of Eq. (1). The mean of the meridional transport at $75^{\circ} \mathrm{N}$ is shown in Fig. 5a. The main positive meridional transport across $75^{\circ} \mathrm{N}$ occurs at about $60^{\circ} \mathrm{W}$ and about $150^{\circ} \mathrm{E}$. Strongest negative meridional transport across $75^{\circ} \mathrm{N}$ occurs at about $120^{\circ} \mathrm{W}$.

However, more important are the anomalies of the respective pathways. Figure $5 b, c$, and d show the meridional MSE transport anomalies at $75^{\circ} \mathrm{N}$ at each longitude for the three transport pathways. The amplitude of the respective meridional transports is a measure of the general energy content (see Eq. 1).

Note that the standard deviation is of the order of $0.2 \mathrm{TW}$ due to the daily data the corresponding group used that is highly variable. For the composite of the North Atlantic pathway (red, Fig. 5b) we have maximum positive anomalies of the meridional MSE transport from $50^{\circ} \mathrm{W}$ to $50^{\circ} \mathrm{E}$, and negative anomalies from $60^{\circ} \mathrm{E}$ to $140^{\circ} \mathrm{W}$. The North Pacific pathway (blue, Fig. 5d) is connected to positive transport anomalies from $80^{\circ} \mathrm{E}$ to $170^{\circ} \mathrm{W}$. This corresponds to the described pathway: originating from the North Pacific and going over eastern Russia to the central Arctic. The Siberian pathway (green, Fig. 5c) shows positive anomalies from 180 to $60^{\circ} \mathrm{W}$ and from 30 to $100^{\circ} \mathrm{E}$.

\subsection{Trend of transport pathways}

Overall, during the analysed time period the North Atlantic pathway occurs about $32 \%$, the North Pacific pathway about 

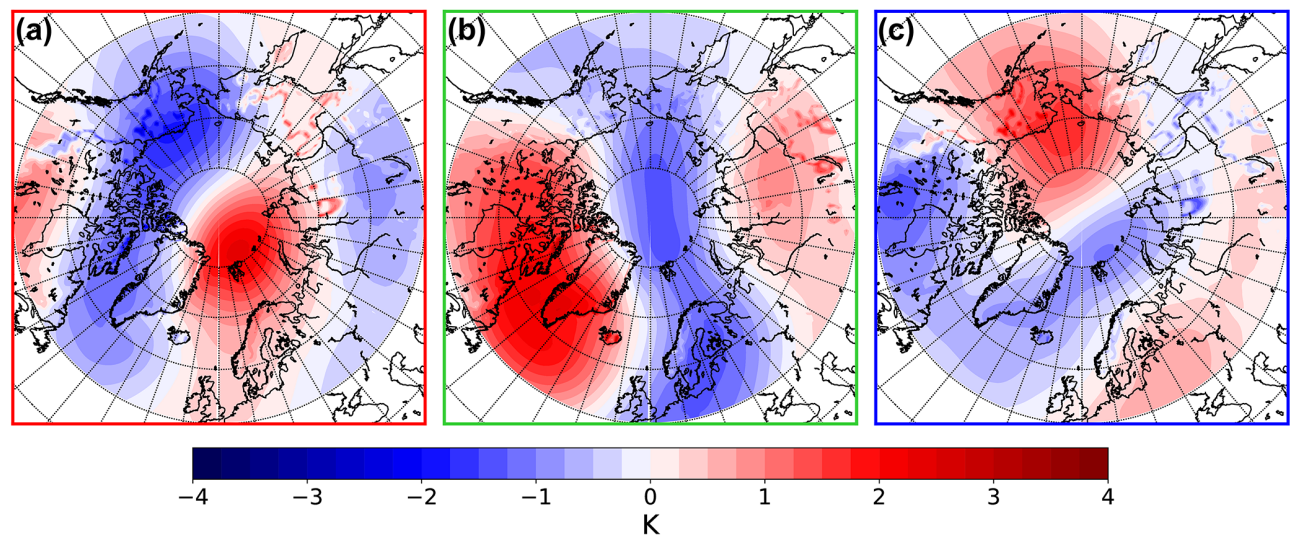

Figure 4. Composite of vertically averaged (surface to $200 \mathrm{hPa}$ ) potential temperature minus the mean of the winter mean period from 1979 to 2016.
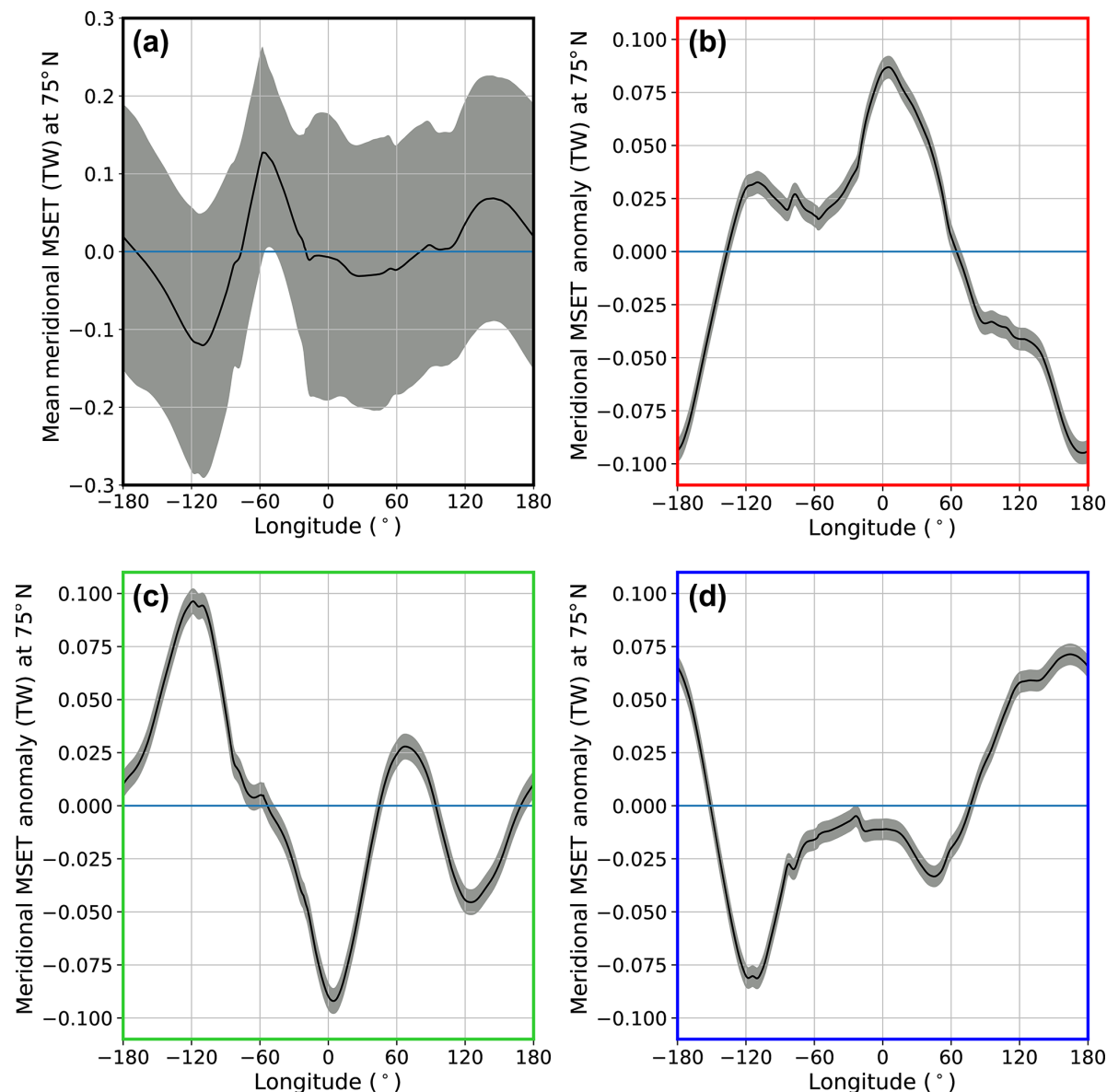

Figure 5. (a) Mean vertically integrated (surface to $200 \mathrm{hPa}$ ) meridional MSE transport (MSET) at $75^{\circ} \mathrm{N}$ in terawatts (TW), grey shading shows the daily standard deviation. Composite of meridional MSE transport anomalies at $75^{\circ} \mathrm{N}$ given in TW for each of the three pathways: (b) North Atlantic pathway, (c) Siberian pathway, and (d) North Pacific pathway. Positive signs denote a transport anomaly to the north, negative signs denote a transport anomaly to the south, and grey shading shows the standard error. 

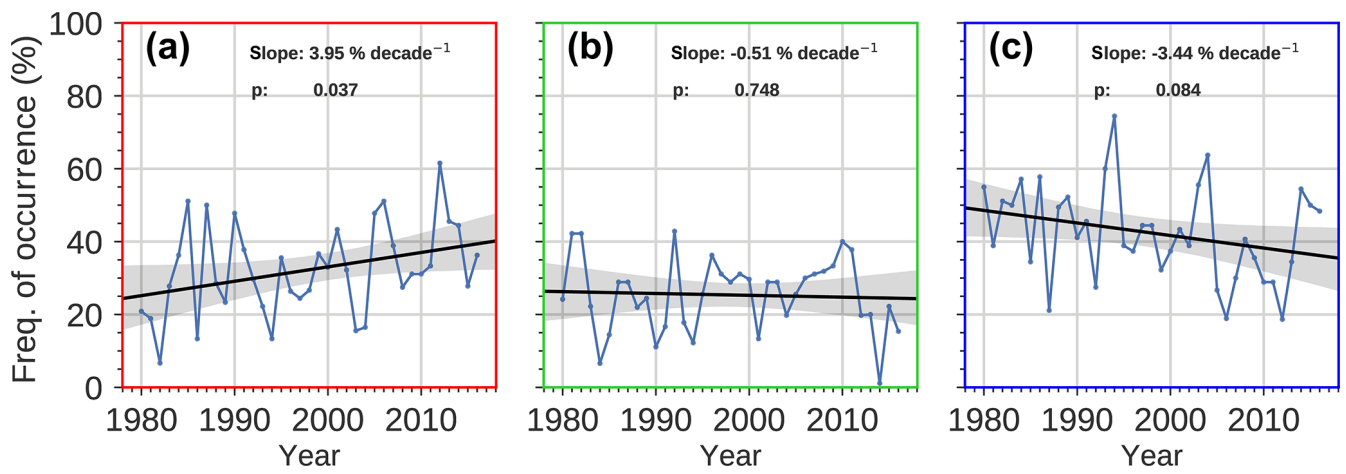

Figure 6. Frequency of occurrence for each transport pathway group according to the colouring (Fig. 1). The blue line shows the frequency of occurrence for each winter from 1979 to 2015 . The black line shows the linear trend line. Greyshading shows the $95 \%$ confidence intervals for the trends derived via bootstrap resampling. $p$ values according to a two-sided $t$ test are shown in the respective panels.

$42 \%$, and the Siberian pathway about $25 \%$ of the time. For each of the three groups the relative frequency of occurrence was calculated for each winter, and the respective time series are shown in Fig. 6.

A positive trend has been found for the North Atlantic pathway (Fig. 6a), a negative trend for the North Pacific pathway (Fig. 6c), and no trend for the Siberian pathway (Fig. 6b). Note that the trends for each of the three patterns are not independent of each other. We also note that the positive and negative trends shown in Fig. 6a and c are not robust, and that there is a small probability they might indeed be different than those derived from the linear fit.

\section{5 $2 \mathrm{~m}$ temperature trends}

Comparing the general $2 \mathrm{~m}$ temperature trend with the resulting $2 \mathrm{~m}$ temperature anomalies (due to different transport pathways) indicates to which degree heat transport might play a role in the warming of the Arctic. The general $2 \mathrm{~m}$ temperature trends for the winter season during the analysed time period is shown in Fig. 7a. The trends were derived through a Theil-Sen regression, which is robust against outliers.

Generally, it can be seen that the trend exceeds $3.5 \mathrm{~K} \mathrm{decade}^{-1}$ for the region east of Svalbard. The largest positive trends are found for regions of the Barents Sea, the Kara Sea, the Laptev Sea, and the Baffin Bay. Negative temperature trends occur over Siberia, but only for very small regions.

To calculate the influence of changes in transport pathways we calculated the weighted average of the temperature anomaly of the North Atlantic pathway and the negative of the temperature anomaly of the North Pacific pathway (Fig. 7b). This was done to take into account the influence of an increased occurrence frequency of the North Pacific pathway and a decrease in occurrence frequency for the North Pacific pathway, and thus to analyse the possible change in temperature according to a trend in the transport pathways. Each of the temperature anomaly fields was weighted by the rela- tive frequency of occurrence shown in Fig. 2. The Siberian pathway was not included as it does not show a trend in the occurrence frequency. This new composite shows similar features compared to the temperature anomaly of the North Atlantic pathway (Fig. 3a), which is owing to the fact that the temperature anomalies connected to the North Atlantic and North Pacific pathways are typically of opposite sign.

The regions of large temperature anomalies are more confined and weaker than the ones considering single pathways alone. The largest positive temperature anomaly occurs north of Svalbard with up to $3.5 \mathrm{~K}$. Negative anomalies occur over the Bering Strait $(-3.0 \mathrm{~K})$ and north of Lake Baikal $(-2.5 \mathrm{~K})$.

The winter temperature trend shows a strong positive signal east of Svalbard. This signal can partly be seen in the temperature anomaly which also shows a positive signal in this region. A uniform temperature trend is not found for the regions that correspond to lower temperatures with an increased occurrence of the North Atlantic pathway and a decreased occurrence of the North Pacific pathway; see Fig. 7a. This suggests that the temperature anomalies due to the transport changes are counteracted by other processes. Please note that the changes in MSE transport cannot account for the entire temperature trends. Other transports and processes affect the temperature as well, even to a higher degree.

\section{Discussion}

The change of influence and connection of atmospheric circulation with surface temperature is a highly discussed topic, especially in terms of the increased temperature rise in the Arctic. Here we grouped data according to distinct pathways based on SOM analysis, and looked at related temperatures and the respective trends of the pathways.

It has to be noted that the linkage between the analysed vertically integrated MSE and $2 \mathrm{~m}$ temperature anomalies is not straightforward. The strongest influence of the energy transports on the surface air temperature is delayed by about 

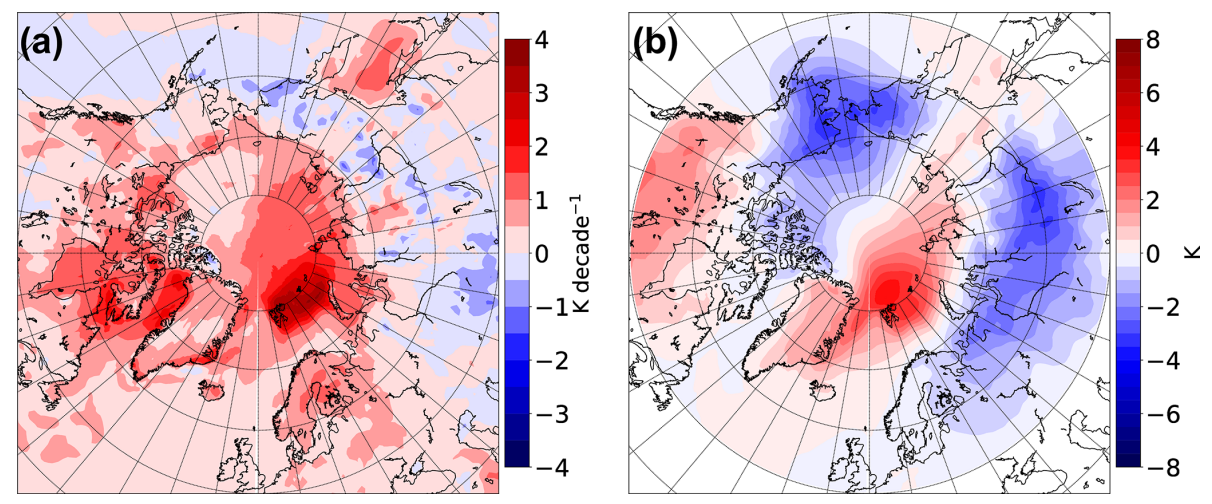

Figure 7. (a) $2 \mathrm{~m}$ temperature trends for the winter mean, calculated for the winters from 1979/80 to 2015/16. Trends are given in kelvin per decade. (b) Composite of $2 \mathrm{~m}$ temperature anomalies from the North Atlantic pathway and the negative of the North Pacific pathway temperature anomalies as provided in Fig. 3, weighted by their relative frequency of occurrence (Fig. 2 top right numbers).

5 days (Graversen, 2006), but in this study we did not consider the persistence of each pattern. However, within this study the focus was to connect the distinct pathways to the concurrent $2 \mathrm{~m}$ temperatures and to get an idea of the conditions in connection with the distinct pathways.

The increase in frequency of transports through the northern Atlantic, as shown for the North Atlantic pathway, has also been found by Dahlke and Maturilli (2017). They analysed the transports of air masses to the region of Ny-Ålesund using backward trajectories. They were able to find a more frequent source region of air masses in the North Atlantic, while we could show that the transport through the North Atlantic is becoming more frequent. Dahlke and Maturilli (2017) identified a positive temperature anomaly over the Svalbard region that is connected to changes in advection of air masses. We find that the increased frequency of the North Atlantic pathway is connected with temperature anomalies that favour a strongly positive anomaly in the central Arctic and strongly negative anomalies over Siberia and the Bering Strait. This is following the transport of heat to the northern regions instead of transport to Siberia.

The vertically averaged potential temperature composites are connected to the $2 \mathrm{~m}$ temperature anomalies. However, the potential temperature anomalies show a more general state of the troposphere, but generally have nearly identical features to the $2 \mathrm{~m}$ temperature anomaly composite.

The $2 \mathrm{~m}$ temperature composite from the North Atlantic pathway has also similar features compared to the cold continents and warm Arctic proposed by Overland et al. (2011). In our analysis negative temperatures anomalies over Canada are not seen, but the cold anomalies over central Siberia, as well as the warm anomaly sector over the central Arctic, are quite well reproduced for transports through the North Atlantic.

Adams et al. (2000) found the transport of heat from the North Atlantic and North Pacific to the Arctic for transient and stationary eddies. Also Messori et al. (2018) found a sys- tematic transport of moisture through the Atlantic sector into the Arctic for warm spells. These warm spells are accompanied by advection of cold air across Siberia, which can be partly seen in the temperature composite of our the North Atlantic pathway. The transports into the Arctic discussed by Messori et al. (2018) are comparable with the transports shown in our results. The general trend of increased northward transport of air can also be seen in regional analysis by Mattingly et al. (2016). They focused on the moisture transport over Greenland. Their analysis shows an increase in moist states over Greenland, which are partly connected to more northward transports. Rinke et al. (2017) analysed extreme cyclone events in the Arctic wintertime from measurements at Ny-Ålesund and from ERA-Interim reanalysis. They found that the number of extreme cyclone events increases. On days with extreme cyclone events at Ny-Ålesund the temperature anomaly pattern looks similar to the temperature pattern shown in the North Atlantic sector for the North Atlantic pathway. This suggests that the origin of the extreme cyclones analysed in Rinke et al. (2017) might be connected to increased transport through the North Atlantic sector to Svalbard.

Woods et al. (2013) analysed poleward moisture intrusions across $70^{\circ} \mathrm{N}$ for winter months using ERA-Interim reanalyses. The concentration of these intrusions were found to be at latitudinal regions of the Labrador Sea, the North Atlantic, and the Barents-Kara Sea and the Pacific. These regions are partly represented in the pathways shown in this work: the general intrusions through the Atlantic and Pacific are captured by the North Atlantic and North Pacific pathway. Intrusions through the Barents-Kara Sea seem to be captured also by the North Pacific pathway, while the intrusions through the Labrador Sea cannot be distinguished easily within the pathways. However, we considered MSE transport instead of only the latent heat transport. Specifically for December and January, Woods and Caballero (2016) could show a positive trend of the total number of intrusions and their connection to 
the surface air temperature and sea ice cover. The largest influences in temperature were observed over the Barents Sea. They showed that the intrusions show typical directions from the North Atlantic into the Barents Sea. The Barents Sea region shows positive temperature anomalies for the North Atlantic pathway, which features a positive trend. These connections are in agreement with the discussed literature.

For the winter months, Cassano et al. (2006) were able to connect SLP patterns with lower pressure over the Bering Strait and the North Atlantic, and higher pressure over Siberia with a temperature anomaly that shares very similar features to those of the North Atlantic pathway found in the work presented here.

The frequency of occurrence of the North Pacific pathway has decreased during the last decades. This is connected with less frequent negative temperature anomalies over the central Arctic. For the winter Matthes et al. (2015) show that the number of cold spell events is decreasing over Scandinavia and northern Canada, while for Siberia also regions with an increase in cold spells could be found. A strong significant increase in warm spells is shown over Scandinavia. Matthes et al. (2015) analysed the trends for warm and cold spells over the land masses and islands in the Arctic using daily station data and ERA-Interim reanalysis. Looking at the trend of regional temperature extremes at Ny-Ålesund, Wei et al. (2015) could show that cold extremes have a negative trend and warm extremes have a positive trend. These results agree with the connection of the North Pacific pathway (North Atlantic pathway) to cold (warm) temperature anomalies and a decrease (increase) in frequency of occurrence.

We compared the resulting mean temperature anomalies for the general change in transport - decrease in occurrence frequency of North Pacific pathway and increase in occurrence frequency of North Atlantic pathway - with the general temperature trend for the winter season from 1979/80 to $2015 / 16$. We found trends over $3.5 \mathrm{~K} \mathrm{decade}^{-1}$ for the general temperature trend in winter west of Svalbard. Graversen (2006) analysed the influence of the atmospheric northward energy transport on the surface air temperature for ERA40 reanalysis for the years 1958 to 2001 . He found that the atmospheric northward energy transport addresses about $0.15 \mathrm{~K}_{\text {decade }}{ }^{-1}$ over Svalbard. Compared to our analysed time frame this would add up to about $0.6 \mathrm{~K}$ anomaly over Svalbard. We identified a positive temperature anomaly of about $3.0 \mathrm{~K}$ over Svalbard, which is about $2.4 \mathrm{~K}$ more than that explained by the total atmospheric northward energy transport. Due to finding connected temperature fields for the distinct transport pathways, we are able to see all influences of the atmosphere under these specific pathways, and not only the specific influence of the northward energy transport which was analysed by Graversen (2006).

It was found that in regions where the change in transport will favour negative temperature anomalies (Siberia and Bering Strait), the temperature trend is not as uniform. For regions north and east of Svalbard the change in transport is connected to positive temperature anomalies that also coincide with regions of positive trends in temperature. Comparing the combined composite of temperature anomalies connected to the changes in the major transport pathways (Fig. 7b) to the temperature anomalies of the Siberian pathway (Fig. 3b) shows that in general the central Arctic tends to become warmer while the Bering Strait tends to become cooler in relation to the change in transport. So in general, the change of transports would lead to more frequent negative temperature anomalies over the Bering Strait and Siberia. These cannot be seen in the trends shown in Fig. 7a. Our results show the expected geographic distribution of surface temperature anomalies that coincide with these changes in the transport. These results also provide a good example where the surface trend is influenced by a lot of processes and cannot be influenced solely by heat transport.

\section{Summary and conclusion}

Using the SOM method we were able to find intrinsic MSE transport patterns within the MSE transport fields and used them as a guide for our analysis. Three distinct transport pathways were extracted from the SOM analysis: the North Atlantic pathway, the Siberian pathway, and the North Pacific pathway. The North Atlantic pathway is connected to transports through the North Atlantic into the Arctic, the North Pacific pathway is connected to transports that originate from the North Pacific and enter the Arctic through eastern Siberia, and the Siberia pathway features transports through the Arctic from central Siberia. We analysed the temperature anomalies that are related to the different transport pathways. This type of analysis helps to get a more complete view of the atmosphere during these different transport pathways.

We conclude that during the last decades the transport through the North Atlantic into the Arctic has increased. These North Atlantic pathways are connected to positive temperature anomalies over the Arctic, and negative temperature anomalies over the Bering Strait and central Siberia. This shows that relating temperature anomalies based on the transport alone favours an increased pattern of warm Arctic and cold continents. Thus, it can be stated that the warm Arctic and cold continents pattern is partly controlled by the increased northward MSE transport through the North Atlantic.

A question that still remains open is the question of causality. To what degree the change in the MSE transports and circulation is changing the temperatures in a warming Arctic and to what degree the temperature change is influencing the heat transports and circulation cannot be decided based on SOM analysis alone. 
Data availability. ERA-Interim reanalyses data have been provided by ECMWF https://apps.ecmwf.int/datasets/ (ECMWF, 2017).

Author contributions. DM performed the data analysis and wrote the first draft of the manuscript. CJ initiated the project and made contributions to the results interpretation and manuscript writing.

Competing interests. The authors declare that they have no conflict of interest.

Acknowledgements. We gratefully acknowledge the funding by the Deutsche Forschungsgemeinschaft (DFG): project no. $268020496-$ TRR 172, within the Transregional Collaborative Research Center "ArctiC Amplification: Climate Relevant Atmospheric and SurfaCe Processes, and Feedback Mechanisms (AC) ${ }^{3}$ " in the sub-project D01. We thank Annette Rinke, AWI Potsdam, for helpful discussions and comments. We want to thank the anonymous reviewer and Rodrigo Caballero for their comments that very much helped us to improve the paper.

Review statement. This paper was edited by Heini Wernli and reviewed by Rodrigo Caballero and one anonymous referee.

\section{References}

Adams, J. M., Bond, N. A., and Overland, J. E.: Regional variability of the Arctic heat budget in fall and winter, J. Climate, 13, 3500-3510, https://doi.org/10.1175/15200442(2000)013<3500:RVOTAH>2.0.CO;2, 2000.

Cassano, J. J., Petteri, U., and Amanda, L.: Changes in synoptic weather patterns in the polar regions in the twentieth and twentyfirst centuries, part 1: Arctic, Int. J. Climatol., 26, 1027-1049, https://doi.org/10.1002/joc.1306, 2006.

Chaudhuri, A. H., Ponte, R. M., and Nguyen, A. T.: A comparison of atmospheric reanalysis products for the Arctic Ocean and implications for uncertainties in air-sea fluxes, J. Climate, 27, 5411-5421, https://doi.org/10.1175/JCLI-D-13-00424.1, 2014.

Collins, W. D., Rasch, P. J., Boville, B. A., Hack, J. J., McCaa, J. R., Williamson, D. L., Briegleb, B. P., Bitz, C. M., Lin, S.-J., and Zhang, M.: The Formulation and Atmospheric Simulation of the Community Atmosphere Model Version 3 (CAM3), J. Climate, 19, 2144-2161, https://doi.org/10.1175/JCLI3760.1, 2006.

Dahlke, S. and Maturilli, M.: Contribution of atmospheric advection to the amplified winter warming in the arctic north atlantic Region, Adv. Meteorol., 2017, 4928620, https://doi.org/10.1155/2017/4928620, 2017

Dee, D. P., Uppala, S. M., Simmons, A. J., Berrisford, P., Poli, P., Kobayashi, S., Andrae, U., Balmaseda, M. A., Balsamo, G., Bauer, P., Bechtold, P., Beljaars, A. C. M., van de Berg, L., Bidlot, J., Bormann, N., Delsol, C., Dragani, R., Fuentes, M., Geer, A. J., Haimberger, L., Healy, S. B., Hersbach, H., Hólm, E. V., Isaksen, L., Kållberg, P., Köhler, M., Matricardi, M., McNally,
A. P., Monge-Sanz, B. M., Morcrette, J.-J., Park, B.-K., Peubey, C., de Rosnay, P., Tavolato, C., Thépaut, J.-N., and Vitart, F.: The ERA-Interim reanalysis: configuration and performance of the data assimilation system, Q. J. Roy. Meteor. Soc., 137, 553-597, https://doi.org/10.1002/qj.828, 2011.

ECMWF: ERA interim, daily model levels, ECMWF, available at:, https://apps.ecmwf.int/datasets/data/interim-full-daily/ levtype $=\mathrm{ml} /$ (last access: 21 March 2019), 2017.

Gillet, N. P., Zwiers, F. W., Weaver, A. J., and Stott, P. A.: Detection of human influence on sea-level pressure, Nature, 422, 292-294, https://doi.org/10.1038/nature01487, 2003.

Graversen, R. G.: Do changes in the midlatitude circulation have any impact on the Arctic surface air temperature trend?, J. Climate, 19, 5422-5438, https://doi.org/10.1175/JCLI3906.1, 2006.

Hazeleger, W., Wang, X., Severijns, C., Ştefănescu, S., Bintanja, R., Sterl, A., Wyser, K., Semmler, T., Yang, S., van den Hurk, B., van Noije, T., van der Linden, E., and van der Wiel, K.: EC-Earth V2.2: description and validation of a new seamless earth system prediction model, Clim. Dynam., 39, 2611-2629, https://doi.org/10.1007/s00382-011-1228-5, 2012.

Higgins, E. M. and Cassano, J. J.: Impacts of reduced sea ice on winter Arctic atmospheric circulation, precipitation, and temperature, J. Geophys. Res.-Atmos., 114, D16107, https://doi.org/10.1029/2009JD011884, 2009.

Kohonen, T.: The self-organizing map, Neurocomputing, 21, 1-6, https://doi.org/10.1016/S0925-2312(98)00030-7, 1998.

Linden, E. C., Bintanja, R., and Hazeleger, W.: Arctic decadal variability in a warming world, J. Geophys. Res.-Atmos., 122, 56775696, https://doi.org/10.1002/2016JD026058, 2017.

Liu, Y. and Weisberg, R. H.: A review of Self-Organizing Map applications in meteorology and oceanography, InTech, https://doi.org/10.5772/13146, 2011.

Liu, Y., Weisberg, R. H., and Mooers, C. N. K.: Performance evaluation of the self-organizing map for feature extraction, J. Geophys. Res.-Oceans, 111, C05018, https://doi.org/10.1029/2005JC003117, 2006.

Lynch, A. H., Serreze, M. C., Cassano, E. N., Crawford, A. D., and Stroeve, J.: Linkages between Arctic summer circulation regimes and regional sea ice anomalies, J. Geophys. Res.-Atmos., 121, 7868-7880, https://doi.org/10.1002/2016JD025164, 2016.

Matthes, H., Rinke, A., and Dethloff, K.: Recent changes in Arctic temperature extremes: warm and cold spells during winter and summer, Environ. Res. Lett., 10, 114020, https://doi.org/10.1088/1748-9326/10/11/114020, 2015.

Mattingly, K. S., Ramseyer, C. A., Rosen, J. J., Mote, T. L., and Muthyala, R.: Increasing water vapor transport to the Greenland Ice Sheet revealed using self-organizing maps, Geophys. Res. Lett., 43, 9250-9258, https://doi.org/10.1002/2016GL070424, 2016.

Messori, G., Woods, C., and Caballero, R.: On the drivers of wintertime temperature extremes in the high Arctic, J. Climate, 31, 1597-1618, https://doi.org/10.1175/JCLI-D-17-0386.1, 2018.

Overland, J. E., Wood, K. R., and Wang, M.: Warm Arctic - cold continents: climate impacts of the newly open Arctic Sea, Polar Res., 30, 15787, https://doi.org/10.3402/polar.v30i0.15787, 2011.

Reusch, D. B., Alley, R. B., and Hewitson, B. C.: Relative Performance of Self-Organizing Maps and Principal Component Analysis in Pattern Extraction from Synthetic Climatological Data, 
Polar Geo., 29, 188-212, https://doi.org/10.1080/789610199, 2005.

Rinke, A. and Dethloff, K.: Simulated circum-Arctic climate changes by the end of the 21st century, Global Planet. Change, 62, 173-186, https://doi.org/10.1016/j.gloplacha.2008.01.004, 2008.

Rinke, A., Maturilli, M., Graham, R. M., Matthes, H., Handorf, D., Cohen, L., Hudson, S. R., and Moore, J. C.: Extreme cyclone events in the Arctic: Wintertime variability and trends, Environ. Res. Lett., 12, 094006, https://doi.org/10.1088/17489326/aa7def, 2017.

Screen, J. A., Deser, C., Simmonds, I., and Tomas, R.: Atmospheric impacts of Arctic sea-ice loss, 1979-2009: separating forced change from atmospheric internal variability, Clim. Dynam., 43, 333-344, https://doi.org/10.1007/s00382-013-1830-9, 2014.

Simmons, A. J. and Paul, P.: Arctic warming in ERA-Interim and other analyses, Q. J. Roy. Meteor. Soc., 141, 1147-1162, https://doi.org/10.1002/qj.2422, 2015.

Skific, N., Francis, J. A., and Cassano, J. J.: Attribution of projected changes in atmospheric moisture transport in the Arctic: A self-organizing map perspective, J. Climate, 22, 4135-4153, https://doi.org/10.1175/2009JCLI2645.1, 2009.

Stroeve, J. C., Serreze, M. C., Holland, M. M., Kay, J. E., Malanik, J., and Barrett, A. P.: The Arctic's rapidly shrinking sea ice cover: a research synthesis, Climatic Change, 110, 1005-1027, https://doi.org/10.1007/s10584-011-0101-1, 2012.

Vinogradova, A.: Meridional mass and energy fluxes in the vicinity of the Arctic border, Izv. Atmos. Ocean Phys., 43, 281-293, https://doi.org/10.1134/S0001433807030036, 2007.
Wei, T., Minghu, D., Bingyi, W., Changgui, L., and Shujie, W.: Variations in temperature-related extreme events (19752014) in Ny-Ålesund, Svalbard, Atmos. Sci. Lett., 17, 102-108, https://doi.org/10.1002/asl.632, 2015.

Wendisch, M., Brückner, M., Burrows, J., Crewell, S., Dethloff, K., Ebell, K., Lüpkes, C., Macke, A., Notholt, J., Quaas, J., Rinke, A., and Tegen, I.: Understanding causes and effects of rapid warming in the Arctic, EOS, 98, 22-26, https://doi.org/10.1029/2017EO064803, 2017.

Wittek, P., Gao, S. C., Lim, I. S., and Zhao, L.: somoclu: an efficient distributed library for self-organizing maps, J. Stat. Softw., 78, 1-21, https://doi.org/10.18637/jss.v078.i09, 2017.

Woods, C. and Caballero, R.: The Role of Moist Intrusions in Winter Arctic Warming and Sea Ice Decline, J. Climate, 29, 44734485, https://doi.org/10.1175/JCLI-D-15-0773.1, 2016.

Woods, C., Caballero, R., and Svensson, G.: Large-scale circulation associated with moisture intrusions into the Arctic during winter, Geophys. Res. Lett., 40, 4717-4721, https://doi.org/10.1002/grl.50912, 2013.

Yoshimori, M., Abe-Ouchi, A., and Laîné, A.: The role of atmospheric heat transport and regional feedbacks in the Arctic warming at equilibrium, Clim. Dynam., 49, 3457-3472, https://doi.org/10.1007/s00382-017-3523-2, 2017. 